\title{
GAMBARAN PENGETAHUAN IBU TENTANG PEMANFAATAN BUKU KESEHATAN IBU DAN ANAK (KIA) DI KELURAHAN WANASARI RW. O13 KABUPATEN BEKASI
}

\author{
Karminingsih*, Latifah, Febriyanti Ade Saputri \\ Jurusan Kebidanan Program Studi Kebidanan D-3 \\ Sekolah Tinggi Ilmu Kesehatan Bani Saleh \\ *email: karminingsih@stikesbanisaleh.ac.id
}

\begin{abstract}
ABSTRAK
Masih rendahnya pemanfaatan buku KIA masih terkendala oleh rendahnya pengetahuan dan sikap ibu tentang manfaat dari buku KIA dan sebagian ibu juga menganggap hal-hal yang berhubungan dengan buku KIA hanya sekedar buku catatan pemeriksaan (Yayu, dkk,2015).4 Tujuan penelitian ini adalah untuk mengetahui gambaran pengetahuan dan pemanfaatan Buku Kesehatan Ibu dan Anak (KIA) di Kelurahan Wanasari Rw.013 Kabupaten Bekasi tahun 2020. Variabel independen nya adalah pengetahuan dan variabel dependen nya adalah pemanfaatan buku KIA. Metode penelitian yang digunakan adalah metode deskriptif dengan pendekatan potong lintang. Sampel penelitian ini adalah semua ibu yang mempunyai balita di Kelurahan Wanasari RW. 013 pengambilan sampel dilakukan dengan teknik total sampling dengan responden dalam kriteria inklusi berjumlah 30 responden.pengambilan data menggunakan data primer. Analisis data meliputi univariat dengan melakukan uji distribusi frekuensi. Hasil penelitian menunjukan bahwa berdasarkan karakteristik yaitu usia yang lebih banyak 26-30 tahun sebanyak 15 responden (50,0\%). Berdasarkan karakteristik pendidikan adalah pendidikan rendah (tamat SD, tamat SMP) sebanyak 17 responden $(56,7 \%)$. Berdasarkan menurut karakteristik pekerjaan yaitu yang tidak bekerja sebanyak 19 responden (63,3\%). Berdasarkan Pengetahuan ibu yaitu berpengetahuan cukup sebanyak 12 responden $(40,0 \%)$. Dan untuk pemanfaatan buku KIA sebanyak 19 responden $(63,3 \%)$. Kesimpulannya di Kelurahan Wanasari RW.013 tahun 2020 responden memanfaatkan buku KIA dan memiliki pengetahuan dengan baik.
\end{abstract}

Kata kunci: Pemanfaatan buku KIA, pengetahuan ibu.

\begin{abstract}
The low utilization of the KIA handbook is still constrained by the low knowledge and attitudes of mothers about the benefits of the KIA handbook and some women also think that matters relating to the KIA book are merely examination notes (Yayu, et al, 2015) .4 The purpose of this study is to know a description of the knowledge and utilization of the Maternal and Child Health Book (KIA) in Wanasari Village Rw.013 Bekasi. The independent variable is knowledge and the dependent variable is the use of the KIA book. The research method used is descriptive method with a cross sectional approach. The sample of this research is all mothers who have toddlers in Wanasari Village RW. 013 sampling was done by total sampling technique with respondents in the inclusion criteria totaling 30 respondents. Data retrieval using primary data. The data analysis includes univariate by doing the frequency distribution test. The results showed that based on the characteristics, namely the age of 26-30 years old as many as 15 respondents (50.0\%). Based on the characteristics of education is low education (graduated from elementary school, graduated from junior high school) as many as 17 respondents (56.7\%). Based on the job characteristics, there were 19 respondents (63.3\%) who did not work. Based on the mother's knowledge, 12 respondents (40.0\%) had sufficient knowledge. And for the use of the KIA book, there were 19 respondents (63.3\%). The conclusion is in Wanasari Village RW. 013 in 2020, respondents used the KIA book and had good knowledge.
\end{abstract}

Keywords: utilization of the KIA book, maternal knowledge. 
Jurnal Kesmas Prima Indonesia

Vol. 3 No. 1 (2021)

\section{PENDAHULUAN}

Menurut data World Health Organization (WHO) tahun 2015, angka kematian ibu di dunia pada tahun 2015 adalah 216 per 100.000 kelahiran hidup atau diperkirakan jumlah kematian ibu adalah 303.000 kematian dengan jumlah tertinggi berada di negara berkembang yaitu sebesar 302.000 kematian. Angka kematian ibu di negara berkembang 20 kali lebih tinggi dibandingkan angka kematian ibu di negara maju yaitu 239 per 100.000 kelahiran hidup sedangkan di negara maju hanya 12 per 100.000 kelahiran hidup pada tahun 2015. Kematian ibu di Indonesia tahun 2013 masih didominasi oleh tiga penyebab utama kematian yaitu perdarahan sebesar 30,13\%, hipertensi dalam kehamilan sebesar $27,1 \%$, dan infeksi sebesar $7,3 \%$. Partus lama juga merupakan Fakultas Kedokteran Universitas Andalas. Salah satu penyebab kematian ibu di Indonesia yang angka kejadiaannya terus meningkat yaitu $1 \%$ pada tahun $2010,1,1 \%$ pada tahun 2011 , dan $1,8 \%$ pada tahun $2012 .{ }^{1}$

Hasil Survey Dasar Kesehatan Indonesia (SDKI) tahun 2012. Mengatakan bahwa AKI mengalami peningkatan yang signifikan sebesar 228 per 100.000 kelahiran hidup menjadi 359 per 100.000 kelahiran hidup. Survei Demografi dan Kependudukan Indonesia tahun 2017, menunjukkan Angka Kematian Ibu sebesar 359/100.000 kelahiran hidup.3 Masih rendahnya pemanfaatan buku KIA masih terkendala oleh rendahnya pengetahuan dan sikap ibu tentang manfaat dari buku KIA dan sebagian ibu juga menganggap hal-hal yang berhubungan dengan buku KIA hanya sekedar buku catatan pemeriksaan. $^{2}$

Berdasarkan penelitian sebelumnya oleh Rina Hanum (2018) mengenai hubungan perilaku ibu dengan pemanfaatan buku kesehatan ibu dan anak di Puskesmas Namu Ukur, dengan pendekatan cross sectional dari 84 responden ibu hamil, didapat hasil pengetahuan responden mayoritas kurang sebanyak 31,9 persen, namun berdasarkan sikap res ponden baik sebanyak 66,1 persen. Buku KIA diharapkan dapat meningkatkan partisipasi masyarakat dalam mengontrol kesehatan ibu. Hasil capaian cakupan buku KIA sampai bulan Desember 2014 dari Dinas Kesehatan Karawang menunjukkan bahwa cakupan Buku KIA yang sebesar $63,49 \%$ dan cakupan K1 yang sebesar 93,37\% menunjukkan perbedaan yang seharusnya adalah sama karena buku KIA diberikan pertama kali saat ibu periksa hamil.5 Berdasarkan hasil penelitian Kusindijah pengetahuan ibu hamil yang memiliki buku Kesehatan Ibu dan Anak (KIA) di Puskesmas Rangkah Surabaya baik 26,3 \% dan 73,2 \% kurang, sedangkan kepemilikan buku Kesehatan Ibu dan
Anak (KIA) terhadap sikap dalam perawatan kehamilan $15,8 \%$ baik dan $84,2 \%$ sedang. ${ }^{4}$

Hasil survey pendahuluan yang telah dilakukan pada bulan Maret 2020 sebanyak 40 orang ibu, kemudian setelah dilakukan wawancara dengan peryataan meliputi isi buku KIA oleh peneliti. Dari 10 ibu yang melakukan pemeriksaan balita total hanya ada 4 orang ibu yang membawa buku KIA,dan total ibu yang tidak membawa ada 6 orang. Dan peneliti bertanya tentang tanda persalinan kepada $10 \mathrm{ibu}$ yang melakukan pemeriksaan balita ada 8 orang ibu yang tidak bisa menjawab dan yang bisa menjawab pertanyaan ada 2 orang ibu yaitu perut mules secara terus menerus dan lama, keluar air ketuban, keluar lendir bercampur darah. Dari hasil wawancara tersebut menunjukkan bahwa lebih banyak ibu yang belum mengetahui tentang buku KIA yang berimbas pada kesehatan ibu dan anak yaitu gawat janin dan kematian.

Berdasarkan latar belakang diatas maka penulis tertarik untuk mengambil judul Bagaimana Gambaran Karakteristik Pengetahuan Ibu Tentang Pemanfaatan Buku Kesehatan lbu dan Anak di Wilayah Kerja Puskesmas Wanasari RW.013.

\section{Metode}

Jenis penelitian ini adalah penelitian deskriptif yang menggambarkan tentang tingkat pengetahuan ibu terhadap pemanfaatan Buku Kesehatan Ibu dan Anak (KIA) dengan pendekatan potong lintang di Kelurahan Wanasari RW. 013 tahun 2020. Populasi yang akan digunakan dalam penelitian ini adalah seluruh ibu di Kelurahan Wanasari RW. 013 tahun 2020. Sampel penelitian ini adalah semua ibu di Kelurahan Wanasari RW. 013 tahun 2020. Dalam pengambilan sampel penelitian ini akan menggunakan teknik total sampling yaitu teknik penentuan sampel dimana seluruh anggota populasi dijadikan sampel. Instrumen ini menggunakan lembar kuesioner berisi pernyataan tingkat pengetahuan dan tentang pengertian, pemanfaatan isi buku KIA mengadopsi dari kuesioner penelitian salmiawati dan musdalina. Kuesioner ini menggunakan Lembar Cheklist $(\sqrt{ })$. Pernyataan ini berisi 25 pertanyaan tertutup jawaban jika benar diberi nilai 1 jika salah diberi nilai 0 .

\section{Hasil}

Dari hasil penelitian yang telah di lakukan di Kelurahan Wanasari RW.013 pada tanggal 02 Juli 03 Juli 2020 mengenai Gambaran pengetahuan ibu tentang pemanfaataan Buku Kesehatan lbu dan Anak (KIA) diperoleh data-data sebagai berikut: 


\section{Karakteristik Responden berdasarkan Pengetahu}

Tabel 1. Distribusi Responden Menurut Pengetahuan Ibu

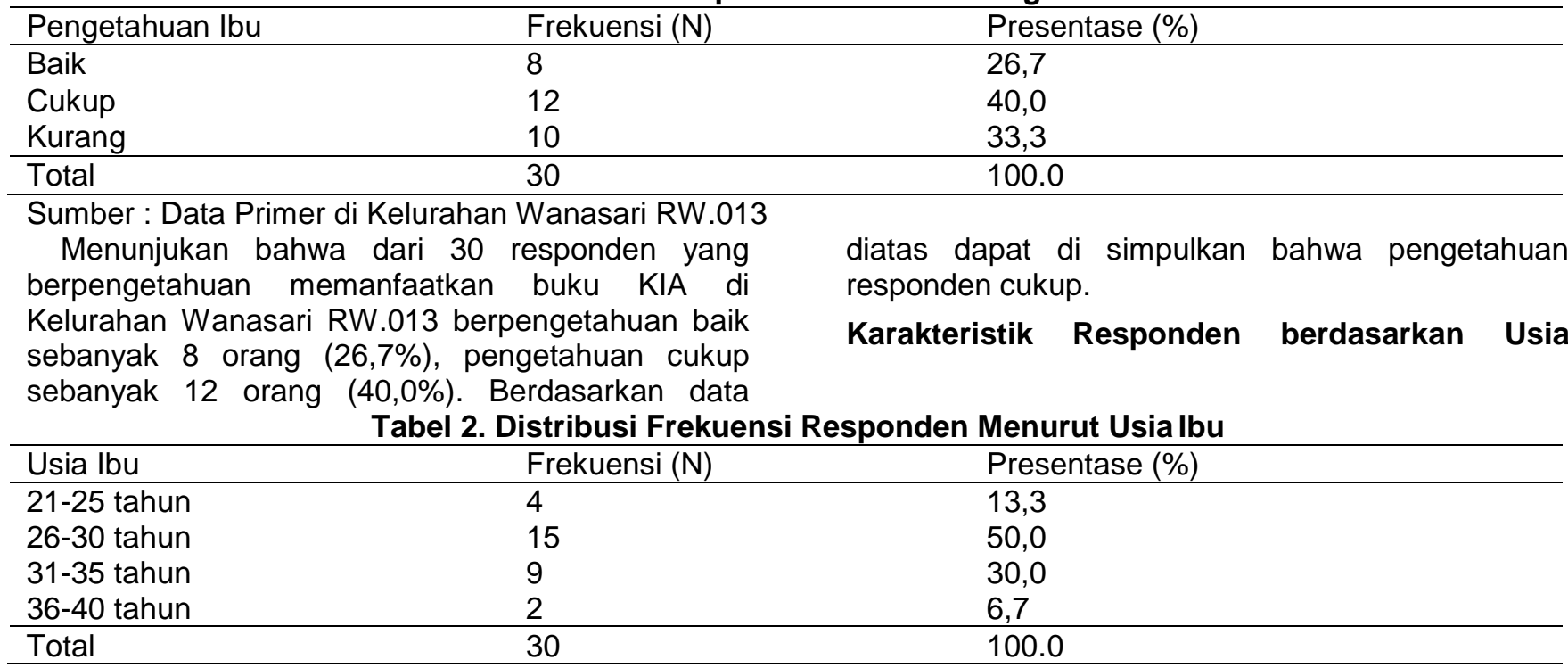

Sumber : Data Primer di Kelurahan Wanasari RW.013

Diketahui bahwa responden yang paling berumur 26-30 tahun sebanyak 15 orang $(22,0 \%)$, responden yang berumur 21-25 tahun sebanyak 4 orang $(13,3 \%)$. Bedarsarkan data di atas dapat disimpulkan bahwa usia responden sebagian besar dalam kategori responden yang tergolong usia produktif yang berdampak pada ingatan informasi yang di peroleh sehingga pengetahuan juga baik.

Karakteristik Responden berdasarkan Pendidikan

Tabel 3. Distribusi Responden Menurut Pendidikan Ibu

\begin{tabular}{lll}
\hline Pendidikan Ibu & Frekuensi $(\mathrm{N})$ & Presentase $(\%)$ \\
\hline Tinggi & 13 & 43,3 \\
Rendah & 17 & 56,7 \\
\hline Total & 30 & 100.0 \\
\hline
\end{tabular}

Sumber : Data Primer di Kelurahan Wanasari RW.013

Diketahui bahwa responden yang berpendidikan tinggi (SMA,Diploma atau Sarjana) sebanyak 13 orang $(43,3 \%)$ dan berpendidikan rendah (SD dan SMP) sebanyak 17 orang (56,7\%). Berdasarkan data diatas dapat disimpulkan bahwa pendidikan

Tabel 4. Distribusi Responden Menurut Pekerjaan Ibu

\begin{tabular}{lll}
\hline Pekerjaan Ibu & Frekuensi (N) & Presentase $(\%)$ \\
\hline Bekerja & 11 & 36,7 \\
Tidak Bekerja & 19 & 63,3 \\
\hline Total & 30 & 100.0 \\
\hline
\end{tabular}

Sumber : Data Primer di Kelurahan Wanasari RW.013

Diketahui bahwa responden yang bekerja sebagai (PNS,Wiraswasta,Guru dII) sebanyak 11 orang $(36,7 \%)$, sedangkan responden yang tidak bekerja (IRT) sebanyak 19 orang (63,3\%). Berdasarkan data responden mayoritas adalah pendidikan rendah (SD dan SMP).

Karakteristik Responden berdasarkan Pekerjaan Ibu diatas dapat disimpulkan bahwa pekerjaan responden mayoritas yang tidak bekerja (IRT). 
Karakteristik Responden berdasarkan Pemanfatan buku KIA

Tabel 5. Distribusi Responden menurut Pemanfaatan buku KIA

\begin{tabular}{lll}
\hline Pemanfaatan buku KIA & Frekuensi $(\mathrm{N})$ & Presentase $(\%)$ \\
\hline Baik & 19 & 63,3 \\
Kurang & 11 & 36,7 \\
\hline Total & 30 & 100.0 \\
\hline
\end{tabular}

Sumber : Data Primer di Kelurahan Wanasari RW.013

Diketahui bahwa responden yang memanfaatkan buku KIA di Kelurahan Wanasari RW.013 memanfaatkan buku KIA yang baik sebanyak 19 orang $(63,3 \%)$, sedangkan memanfaatkan buku KIA yang kurang sebanyak 11 orang $(36,7 \%)$. Berdasarkan data diatas dapat disimpulkan bahwa pemanfaatan responden baik.

\section{Pembahasan \\ Karakteristik Responden Berdasarkan Usia}

Berdasarkan hasil penelitian Nita Farida di Puskesmas Wanakerta, Karawang tahun 2015 didapatkan hasil bahwa karakteristik responden berdasarkan usia adalah lebih banyak responden pada kategori usia 20-35 tahun, yaitu 108 orang $(87,1 \%)$, sedangkan usia 35 tahun berjumlah 16 orang (12,9\%). Dari hasil ini diperoleh usia minimal responden yaitu 16 tahun, dan usia maksimal yaitu 40 tahun, dengan usia rata- rata yaitu 26 tahun. Usia menyatakan proporsi pemanfaatan buku KIA lebih banyak dimanfaatkan oleh responden berusia 35 tahun. Usia adalah waktu lama hidup sesorang yang terhitung sejak lahir. Dalam penelitian ini, usia 20 tahun cenderung lebih memanfaatkan buku KIA karena pada umur tersebut ibu hamil masih merasa bahwa pemeriksaan kehamilan adalah hal yang penting terutama pada kehamilan pertama, sedangkan ibu usia $>35$ tahun cenderung acuh dalam memanfaatkan buku KIA karena telah merasa cukup berpengalaman pada kehamilan sebelumnya. ${ }^{5}$

Berdasarkan hasil analisis yang didapatkan karakteristik responden berdasarkan usia adalah responden yang berusia 21-25 tahun sebanyak 5 orang $(16,7 \%)$, sedangkan responden yang berumur 26-30 tahun sebanyak 15 orang $(22,0 \%)$, responden yang berumur 31-35 sebanyak 6 orang $(20,0 \%)$ dan responden yang berumur 36-40 tahun sebanyak 4 orang $(13,3 \%)$. Dari hasil ini diperoleh usia minimal responden yaitu 31-35 tahun dan usia maksimal yaitu 26-30 tahun karena ibu yang sudah melahirkan akan jauh lebih mengetahui dan memahami.

\section{Karakteristik Pengetahuan \\ Responden Berdasarkan}

Berdasarkan hasil penelitian Nita Farida di Puskesmas Wanakerta, Karawang tahun 2015 didapatkan hasil bahwa karakteristik responden Berdasarkan pengetahuan responden, mayoritas responden mempunyai pengetahuan tinggi yaitu sebanyak 98 orang $(79,0 \%)$, sedangkan responden berpengetahuan rendah adalah 26 orang $(21 \%) .{ }^{5}$

Berdasarkan hasil penelitian (Setyaningrum, 2015). Tingkat pengetahuan yang baik juga ditunjukkan pada ibu dengan primigravida yaitu sebanyak 36 orang $(59,1 \%)$. Hal tersebut sejalan dengan hasil penelitian yang terkait gambaran tingkat pengetahuan, sikap dan praktik ibu hamil terhadap penggunaaan buku KIA sebagai sumber referensi. Pada penelitian tersebut disebutkan bahwa seseorang yang baru pertama kali hamil akan cenderung mencari tahu lebih banyak informasi dan pengetahuan tentang kehamilan. Ibu hamil dengan usia muda atau primigravida biasanya lebih ingin tahu tentang kehamilannya sehingga mereka akan lebih sering membaca atau memahami informasi yang ada di dalam Buku KIA. ${ }^{6}$

Menurut penelitian (Elisa, 2014). Bahwa responden berpengetahuan baik lebih banyak pada responden usia 20-35 tahun yaitu sebanyak 82 orang (54,3\%). Usia 20-35 tahun merupakan usia yang ideal untuk kehamilan dan persalinan. Pada usia ini organ reproduksi telah berkembang dengan baik dan siap untuk menerima terjadinya kehamilan dan persalinan. Selain itu, kematangan emosi dan psikis juga penting untuk menghadapi kehamilan. Kehamilan pada usia muda harus diimbangi dengan kematangan emosi dan psikis sehing siap dalam menjalan proses kehamilan dan persalinan. Sedangkan ibu dengan usia >35 tahun akan lebih acuh dalam hal informasi yang membuat pengetahuannya menjadi berkurang, namun hal ini juga dapat dipengaruhi oleh paritas seseorang. ${ }^{7}$

Menunjukan bahwa dari analisis yang didapat ada 30 responden yang berpengetahuan memanfaatkan buku KIA di Kelurahan Wanasari RW.013 berpengetahuan baik sebanyak 7 orang $(23,3 \%)$, pengetahuan cukup sebanyak 14 orang $(46,7 \%)$ ibu yang berusia $26-30$ tahun merupakan usia yang produktif dan pengalaman melahirkan nya 
Jurnal Kesmas Prima Indonesia

Vol. 3 No. 1 (2021)

sering sehingga di usia tersebut ibu memiliki pengetahuan yang cukup , sedangkan berpengetahuan kurang sebanyak 9 orang $(30,0 \%)$.

\section{Karakteristik Responden Berdasarkan Pendidikan}

Berdasarkan hasil penelitian Nita Farida distribusi pendidikan responden, mayoritas responden berpendidikan tinggi (SMA-PT) sebanyak 103 orang $(83,1 \%)$ sedangkan responden dengan pendidikan SD-SMP adalah sebanyak 21 orang (16,9\%). Berdasarkan distribusi pengetahuan responden, mayoritas responden mempunyai pengetahuan tinggi yaitu sebanyak 98 orang $(79,0 \%)$, sedangkan responden berpengetahuan rendah adalah 26 orang $(21 \%)^{5}$

Berdasarkan hasil penelitian Theresa $F$ Napitupulu , Lina Rahmiati , Dini Saraswati , Ari Indra Susanti, Elsa Pudji Setiawati di wilayah Puskesmas Jatinangor 2017 didapatkan hasil penelitia $n$ ini menunjukan distribusi responden yang mempunyai berdasarkan tingkat pendidikan yaitu responden yang berpendidikan tinggi memiliki pengetahuan baik yang lebih banyak yaitu sebanyak 8 orang $(72,7 \%)$ dan responden berpendidikan rendah lebih sering memanfaatkan buku KIA yaitu sebanyak 57 orang $(65,5 \%)$. Pendidikan merupakan usaha yang dilaukan secara sadar dan terencana untuk mewujudkan suasana dan proses pembelajaran sehingga pendidikan responden dapat mempengaruhi perilaku ibu dalam memanfaatkan buku KIA. Dalam hal ini, ibu dengan pendidikan yang rendah memulai ingin tahu lebih banyak hal sehingga lebih sering membaca ataupun memanfaatkan buku KIA. ${ }^{6}$

Diketahui bahwa responden yang berpendidikan tinggi rata-rata pendidikan terakhinya yaitu SMA sebanyak 14 orang $(46,7 \%)$ dan berpendidikan rendah rata-rata SD dan SMP sebanyak 16 orang $(53,3 \%)$. Berdasarkan data diatas dapat disimpulkan bahwa pendidikan responden mayoritas adalah pendidikan rendah (SD dan SMP) dikarenakan yang berpendidikan rendah lebih banyak punya waktu untuk mebaca dan memahami buku KIA dan ratarata ibu di Kelurahan Wanasari RW.013 mengikuti posyandu.

\section{Karakteristik Responden Berdasarkan Pekerjaan}

Berdasarkan hasil penelitian Theresa $F$ Napitupulu, Lina Rahmiati , Dini Saraswati, Ari Indra Susanti, Elsa Pudji Setiawati di wilayah Puskesmas Jatinangor 2017 Pekerjaan responden, ibu yang bekerja lebih banyak memanfaatkan Karakteristik berdasarkan pekerjaan, ibu yang bekerja memiliki pengetahuan yang lebih baik yaitu sebanyak 26 orang $(61,9 \%)$, dibandingkan dengan ibu hamil yang tidak bekerja yaitu sebesar $49,6 \%$. Hal tersebut dapat dipengaruhi lingkungan pekerjan serta pendidikan yang didapatkan yang selanjutnya mempengaruhi pola pikir, cara berpikir, dan sumber informasi. Pengetahuan dan pengetahuan dapat diperoleh baik secara langsung maupun tidak langsung melalui lingkungan pekerjaan. ${ }^{6}$

Diketahui bahwa responden yang bekerja sebagai (PNS,Wiraswasta,Guru dII) sebanyak 5 orang $(16,7 \%)$, sedangkan responden yang tidak bekerja (IRT) sebanyak 25 orang (83,3\%). Di dapatkan hasil bahwa ibu yang tidak bekerja (IRT) lebih cukup mengetahui dan memanfaatakan buku KIA dikarenakan ada waktu luang untuk membaca dan memahami buku KIA. Sedangkan ibu yang bekerja sebagai guru dan wiraswasta mempunyai kesibukan sehingga menyebabkan kesempatan ibu untuk membaca buku termasuk buku KIA menjadi lebih rendah.

\section{Karakteristik Responden Berdasarkan Pemanfaatan buku KIA}

Berdasarkan hasil penelitian Farida menunjukan ibu primigravida lebih banyak memanfaatkan buku KIA yaitu seabnyak 46 orang (65\%). Hal tersebut dapat terjadi karena ibu dengan kehamilan pertama akan mengalami pengalaman- pengalaman baru, itu sebabnya ibu yang pertama kali hamil akan merasa lebih ingin tahu dibandingkan dengan wanita hamil yang sudah pernah melahirkan sehingga akan lebih sering memanfaatkan buku KIA. Dalam penelitian yang pernah dilakukan oleh Farida mengenai determinan pemanfaatan buku KIA menyatakan ibu primigravia lebih sering memanfaatkan buku KIA. Hal tersebut dikarenakan ibu yang baru pertama kali hamil akan mencaritahu halhal mengenai kehamilannya dan sedang berusaha memahami fungsi dan manfaat buku KIA sebagai pedoman dalam kehamilan, karena ibu meyakini bila manfaat dan fungsi dari buku KIA sangat baik, maka ibu akan memilih untuk selalu membawa buku tersebut ketika pemeriksaan, berusaha membaca dan memahami isi bukunya dan selalu menjaganya. ${ }^{6}$ Hasil penelitian ini diperkuatkan lagi oleh Mayang Sari Ayu (2019). Berdasarkan hasil penelitian ini dengan jumlah responden 50 orang menunjukan pengetahuan ibu hamil baik dengan pemanfaatan buku KIA yang efektif sebanyak 28 orang $(56 \%)$ dibandingkan pengetahuan ibu hamil yang kurang dengan pemanfaatan yang tidak efektif sebanyak 22 orang $(44 \%)^{8}$

Diketahui bahwa responden yang memanfaatkan buku KIA di Kelurahan Wanasari RW.013 memanfaatkan buku KIA yang baik sebanyak 19 orang $(63,3 \%)$, sedangkan memanfaatkan buku KIA yang kurang sebanyak 11 orang (36,7\%). Peneliti 
berpendapat bahwa ibu yang memiliki perilaku baik akan memanfaatkan buku KIA sebagai catatan kesehatan dan sebagai sumber informasi yang berhubungan tentang kesehatan keluarga. Ibu hamil juga dapat mengetahui tanda-tanda bahaya yang dapat mengancam tentang kesehatan ibu selama hamil dari buku KIA. . Buku Kesehatan Ibu dan Anak berisi catatan kesehatan ibu (hamil, bersalin dan nifas) dan anak (bayi baru lahir sampai anak usia 6 tahun) serta berbagai informasi cara memelihara dan merawat kesehatan ibu dan anak. Setiap ibu hamil mendapat 1 (satu) Buku KIA.

\section{Kesimpulan}

Kesimpulan dari penelitian yang dilakukan oleh penulis di Kelurahan Wanasari RW.013 Kabupaten Bekasi Tahun 2020 :

1. Diketahui sebanyak 30 responden di Kelurahan Wanasari RW.013 yang pengetahuan cukup sebanyak 14 orang $(46,7 \%)$.

2. Diketahui sebanyak 30 responden di Kelurahan Wanasari RW.013 yang memanfaatkan buku KIA di Kelurahan Wanasari RW.013 tahun 2020 sebanyak 19 responden $(63,3 \%)$. Dan rata-rata responden memanfaatkan buku KIA dan memiliki pengetahuan yang baik.

\section{Daftar Pustaka}

1. Fakultas Kedokteran Universitas Andalas 1. $2015: 1-6$.

2. Puji Rahayu, Yayu dkk. (2015). Hubungan Pengetahuan dan Sikap lbu Hamil Tentang Tanda Bahaya Kehamilan Terhadap Pemanfaatan buku KIA di UPTD.
Puskesmas Martapura. STIKES Sari Mulia Banjarmasin dan Poltekes Kemenkes Banjarbaru. Jurnal, Vol 13:(15).

3. Hanum,R.(2018). Hubungan Pengetahuan dan Sikap Ibu Hamil Tentang Pemanfaatan Buku KIA di Puskesmas Namu Ukur. Institut Kesehatan Helvetia Medan. Jurnal 1(3): 152-160.

4. Kusindijah.(2012). Hubungan antara pemilikan buku KIA dengan pengetahuan, sikap dan praktik perawatan kehamilan diwilayah kerja Puskesmas Rangkah Surabaya.Embrio Jurnal Kebidanan 1(1): 42-6.

5. Nita Farida, (2015) Determinan Pemanfaatan Buku Kesehatan Ibu dan Anak (KIA) oleh Ibu Hamil di Puskesmas Wanakerta, Kabupaten Karawang. ${ }^{5}$

6. Theresa F, Lina, Dini (2018). Gambaran Pemanfaatan Buku KIA Tentang Pengetahuan Ibu Hamil Mengenai Tanda Bahaya Kehamilan Vol.(3). No. $1^{6}$

7. Elisa. (2014). Umur, Pendidikan, Pekerjaan Dan Tingkat Pengetahuan Ibu Primigravida Tentang Tanda Bahaya Kehamilan Trimester III Di Wilayah Puskesmas Ungaran Kecamatan Ungaran Barat Kabupaten Semarang. Jurnal Keperawatan Maternitas, Volume 2, No. 2, November 2014; 84- 89.

8. Mayang Sari Ayu,(2019). Efektivitas Pemanfaatan Buku Kesehatan Ibu dan Anak Sebagai Media Komunikasi, dukasi dan informasi. Di wilayah Sumatera Utara . Jurnal kedokteran Ibnu Nafis, Vol (8) No.2 tahun 2019. 